\title{
Stanford and Cornell in the frame for B-meson factory
}

Washington. An expert panel will this week assess whether a high-energy physics facility known as the B-meson factory should be built at Stanford (California), at Cornell University (New York) - or not at all.

The 12-strong panel, chaired by $\mathrm{Dr}$ Stanley Kowalski of the Massachusetts Institute of Technology, visited the Stanford Linear Accelerator Center (SLAC) last week and then went straight on to Cornell, quizzing rival project teams on their proposals. The panel will report to the administration next week; Congress has asked for a choice of the best option by 15 July.

Some members of the high-energy physics community are worried that these tight deadlines will not be met, causing the Congress to withdraw the $\$ 36$ million it has been planning to allocate to the project in the coming year. But even as the House of Representatives last week moved to axe funding for other programmes (see opposite), funds for the B-meson factory project survived the appropriation process intact; Congress makes a final decision later in the summer, if and when a site has been chosen.

The purpose of the proposed facility is to create large numbers of B mesons, which can be produced by colliding electrons and positrons. Existing colliders produce Bmesons, but as the particles of opposite charge usually have identical energy, the mesons emerge in random directions. The new objective is to produce a beam of $\mathrm{B}$ mesons, for which purpose unequal energies are necessary. The B-meson factory will therefore tuck a second storage ring, carrying positrons of lesser energy, next to an existing ring at either SLAC or Cornell.

Interest in the production of B-mesons centres on the likelihood that their decay will throw light on the violation of parity and charge-conjugation invariance in the weak nuclear interaction - phenomena which may be crucial in explaining the predominance of matter over anti-matter in the known universe. Because of their large mass, the B-mesons will also be prolific sources of other nuclear particles (hadrons).

Stanford's play for the project is due to lobbying by SLAC's director, Burton Richter, of Californian congressmen, who won funds for it in President Bill Clinton's first budget. SLAC says it would update its 800 metre diameter Positron-Electron Project (PEP) ring (now 13 years old) at a cost of $\$ 161$ million over four years. B-meson detectors would cost a further $\$ 59$ million half from overseas collaborators.

SLAC, a DoE laboratory with 1,400 staff and an annual budget of around $\$ 130$ million, needs the B-meson factory to keep its researchers busy during a slack period be- fore it can renew its main linear accelerator.

The rival bid is cheaper. Cornell says it could upgrade the Cornell Electron Storage Ring (CESR or 'Caesar') to a proper Bmeson factory for just $\$ 110$ million, although but SLAC says the two sets of figures are not directly comparable.

Kowalski insists that the administration and the Congress, not his panel, will eventually choose the winner. He says the panel's job is to evaluate the two proposals "to see if they make for good physics" and to say if the cost estimates "are credible and complete".

NSF and DoE will have a week jointly to decide the outcome, but the Office of Management and Budget and the Office of Science and Technology Policy as well as various congressional interests are certain to take an interest. Just who will make the choice, and how, is unclear: "That's the million dollar question", says Kowalski. "I don't believe there is a formula."

But some observers believe there is a formula: put the B-meson factory in California, where DoE wanted it in the first place. The decision will be "political", according to a prominent physicist who declined to sit on Kowalski's panel.

Karl Berkelman, director of CESR, says on the other hand that he will not be "greatly surprised" if the project is put back on hold. But some supporters are more optimistic: the B-meson factory has few enemies, its costs are manageable and its objectives clear. And if the Superconducting Super Collider is indeed to perish, this more self-effacing project may benefit from Congress's subsequent pangs of guilt.

Colin Macilwain

\section{Push for TB vaccine}

London. The pharmaceutical company Glaxo is to provide $£ 10$ million for a five-year university-based programme of research into tuberculosis - the world's main killer infection, which claims three million victims every year - to be carried out in Britain and South Africa. The funds will support basic research on the development of new vaccines, using the techniques of molecular biology and genetic engineering, and of new antibiotics effective against strains of the tuberculosis bacterium that are resistant to existing treatments. Research institutions collaborating with Glaxo in Britain will be the London School of Hygiene and Tropical Medicine, St Mary's Hospital Medical School and the University of Birmingham. The South African research groups will be based at the University of Cape Town, the University of Stellenbosch and the South African Medical Research Council. D.D.

\section{Yeltsin's two steps to Eureka club membership}

London. Russia's application to join Europe's advanced technology research programme Eureka was approved in principle last week, but several conditions must be met by the Russian government before membership can become a reality.

Eureka was set up at the initiative of the French government in 1985, and now covers more than 800 separate projects involving industrial companies, public laboratories and university research groups in 20 European states. Russia's application was formally agreed by research ministers from the member states in Paris. Among the potential benefits of membership is that of speeding the conversion of Russian military research laboratories to civil goals.

One condition to be satisfied by Russia is that its laws on patents and intellectual property, previously based on the idea that the rights to scientific discovery belong to the state, should come into line with those in Western Europe; President Boris Yeltsin has undertaken to submit a decree to this effect. $\mathrm{He}$ is also required to set up procedures to ensure that civilian technologies imported from the West are not diverted to military purposes, which may be more difficult.

Ironically, Eureka was inspired by the prospect that US industry would benefit from civilian spin-offs from President Reagan's proposed Star Wars programme.

Despite initial scepticism, Eureka is now flourishing. At last week's meeting, 193 new projects, each of which must involve research groups from at least two participating states, were announced, bringing the total investment in Eureka projects over the past eight years to $£ 12$ billion.

An evaluation of Eureka's social and economic impact by experts from 14 countries and co-ordinated by the University of Manchester's programme of Policy Research in Engineering Science and Technology (PREST) shows over 40 per cent of participants in individual projects expect a substantial increase in sales over the next three years, and that 88 per cent will introduce new products. The study confirmed that cooperation tends to be "vertical" (between suppliers and customers) rather than "horizontal" (between competitors).

According to Luke Georghiou of PREST, the evaluation also showed that public funding had been an essential element in ensuring the success of Eureka, in particular by motivating companies to join individual projects. Russia's application for membership follows Hungary's acceptance as a full member last year. In addition, national information points have been set up covering 12 countries in Central and Eastern Europe.

David Dickson 